\title{
Editorial
}

\section{Hydrology and the Environment}

\author{
Kaufui Vincent Wong ${ }^{*}$, J. Modern ${ }^{\#}$ and J. Renewable ${ }^{\#}$
}

\section{Mechanical and Aerospace Engineering Department, University of Miami, Coral Gables, FL, USA}

The theme for the papers in the issue is "Hydrology and the Environment". There is a mix of review papers and research papers. Climate change and water are very important subjects in these times. Hydrology is the science of water, and the environment has water as one of the three principal earthly components, the other two being the air and the earth. Hence, hydrology and the environment would be a good focus at this time.

One paper addresses the issues caused by sea level rise, as seen and predicted by climate change experts [1-3]. Mitigation and adaptation are options to consider, but the author advises against inaction. The new recommendation that is presented is to employ municipal solid waste, in addition to sand, gravel and rocks, as well as an impermeable bottom lining, to build up the low-lying coastal areas. This sanitary landfill would be similar in purpose to the dykes of Holland. These Dutch barrier systems have successfully kept out the North Sea for years.

The other is a review of the richness found in our seas and oceans. Wong suggests to turn to the wealth of the oceans when faced with the problems brought on by the energy-water-food nexus. He recommends that a detailed mapping of the ocean floors be done, especially since we know more about some parts of space than the details of the ocean floors in our own 'spaceship'. Wong, Hutley and Salgado also call for the tapping of wind energy for electricity generation from the West Wind Drift in our southern oceans [4]. They do recognize the many challenges of making that a practicality, but so was 'flying' in another era.

*Address correspondence to this author at the Mechanical and Aerospace Engineering Department, University of Miami, Coral Gables, FL, USA; E-mail: kwong@miami.edu

${ }^{\#}$ These are Co-Editors
There is also a review about the innovative technology brought on by climate change. Since there is climate change with drought issues in regions like California for instance [5], a modern innovation that has been developed which can be adopted is recycling of wastewater for agriculture. This is hardly used in Africa where wastewater recycling hovers in the $1 \%$ range. The Middle East and Northern Africa (MENA), recovers about $30 \%$ of their total water consumption as wastewater [6]. This fact demonstrates convincingly that wastewater recovery is a significant water resource. There are also innovations required to address the issue of crop density and more drought resistant crops [7].

Finally, there is a research paper on algae nutrient relationships to round up this special issue. Chin clearly explains the new method by demonstrating it to a damaged portion of the Halifax river, Daytona, Florida.

\section{REFERENCES}

[1] IPCC, IPCC Fifth Assessment Report. Climate Change 2013, 2013 2014.

[2] IPCC, IPCC Fourth Assessment Report. Climate Change 2007, 2007.

[3] IPCC, IPCC Third Assessment Report. Climate Change 2001, 2001.

[4] Wong KV, Hutley T, Salgado E. Offshore wind power and its potential for development in the west wind drift. IMECE201039825. Proceedings on IMECE 2010, Nov.12-18 2010. Vancouver, BC, CA.

[5] CBS News, Local, "Drought So Bad This California Kid Has Never Seen Rain", http://sanfrancisco.cbslocal.com/2015/05/16/drought-so-bad-some-california-kids-have-never-seen-rain/ [May 16, 2015. Retrieved 5/17/15]

[6] Qadir M. Wastewater production, treatment, and irrigation in middle east and north africa. Irrigation Drainage Syst 2010; 24(1-2): 37.

[7] Lobell DB, Roberts MJ, Schlenker W, et al. Greater sensitivity to drought accompanies maize yield increase in the U.S. Midwest. Science 2014; 344(6183): 516-9.

Received: March 25, 2015
(C) Wong et al.; Licensee Bentham Open.
This is an open access article licensed under the terms of the Creative Commons Attribution Non-Commercial License
(http://creativecommons.org/licenses/by-nc/3.0/) which permits unrestricted, non-commercial use, distribution and reproduction in any medium, provided the work is properly cited. 